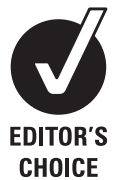

See Editorial, p 267

${ }^{1}$ Department of Cardiology, The Second Affiliated Hospital, Xi'an Jiaotong University School of Medicine, Xi'an, Shaanxi, China ${ }^{2}$ Key Laboratory of Environment and Genes Related to Diseases (Xi'an Jiaotong University), Ministry of Education, China

\section{Correspondence to}

Dr Dengfeng Gao, Department of Cardiology, The Second Affiliated Hospital, Xi'an Jiaotong University School of Medicine, Xi'an, Shaanxi 710004, PR China; gaomedic@163.com

Accepted 19 October 2010 Published Online First 5 December 2010

\title{
Trimetazidine: a meta-analysis of randomised controlled trials in heart failure \\ Dengfeng Gao, ${ }^{1,2}$ Ning Ning, ${ }^{1}$ Xiaolin Niu, ${ }^{1,2}$ Guanghua Hao, ${ }^{1}$ Zhe Meng ${ }^{1}$
}

\begin{abstract}
Objective To explore whether trimetazidine could improve symptoms, cardiac functions and clinical outcomes in patients with heart failure (HF).

Methods A systematic literature search was conducted to identify randomised controlled trials (RCT) of trimetazidine for HF between 1966 and May 2010 in Pubmed, the Cochrane Central Registry of Clinical Trials and EMBASE. Reports of trials were sought that compared trimetazidine with placebo control for chronic $\mathrm{HF}$ in adults, with outcomes including all-cause mortality, hospitalisation, cardiovascular events, changes in cardiac function parameters and exercise
\end{abstract} capacity.

Results 17 trials with data for 955 patients were identified by the literature search. Trimetazidine therapy was associated with a significant improvement in left ventricular ejection fraction in patients with both ischaemic (weighted mean difference (WMD) with placebo $7.37 \%$; 95\% Cl 6.05 to $8.70 ; p<0.01)$ and non-ischaemic HF (WMD 8.72\%; 95\% Cl 5.51 to 11.92 ; $\mathrm{p}<0.01)$. With trimetazidine therapy, left ventricular end-systolic volume was significantly reduced (WMD $10.37 \mathrm{ml}$; 95\% Cl 15.46 to 5.29; $p<0.01$ ) and New York Heart Association classification was improved (WMD 0.41; 95\% Cl 0.51 to $0.31 ; p<0.01$ ) as was exercise duration (WMD, 30.26 s; $95 \%$ Cl 8.77 to $51.75 ; p<0.01$ ). More importantly, trimetazidine had a significant protective effect for all-cause mortality (RR $0.29 ; 95 \% \mathrm{Cl} 0.17$ to $0.49 ; \mathrm{p}<0.00001$ ) and cardiovascular events and hospitalisation (RR 0.42; 95\% Cl 0.30 to $0.58 ; p<0.00001$ ).

Conclusion Trimetazidine might be an effective strategy for treating HF. More studies, especially larger multicentre RCT, are warranted to clarify the effect of trimetazidine on HF.

With more than 5 million prevalent cases and nearly 1 million hospital discharges yearly, heart failure (HF) represents a rapidly growing therapeutic challenge for healthcare providers. $^{1}$ Continual knowledge of the pathophysiological background of HF is fundamental in the management of this complex disease. The past 20 years have seen considerable progress in the treatment of HF, with ACE inhibitors, aldosterone antagonists, $\beta$-receptor blockers and resynchronisation therapy. ${ }^{2}$ However, HF remains a leading cause of morbidity and mortality throughout the world. ${ }^{3}$

Myocardial energy metabolism may be normal in the early stages of HF, but as failure progresses, mitochondrial oxidative metabolism is reduced, and glycolysis is increased with the downregulation of glucose and fatty acid oxidation. ${ }^{4}$ In particular, evidence suggests that with HF, a shift of metabo- lism away from a preference for fatty acid towards more carbohydrate oxidation can improve contractile function, thus slowing the progression of $\mathrm{HF}$ and improving prognosis in patients with $\mathrm{HF}^{5}$

Trimetazidine, a piperazine derivative used as an anti-anginal agent, selectively inhibits long-chain 3-ketoacyl coenzyme A thiolase (the last enzyme involved in $\beta$-oxidation) activity. Trimetazidine has been reported to have a potential benefit in $\mathrm{HF}^{6}$ Trimetazidine may affect myocardial substrate use by inhibiting oxidative phosphorylation and shifting energy production from free fatty acids (FFA) to glucose oxidation. ${ }^{7}$ It may also contribute to the preservation of intracellular levels of phosphocreatine and ATP, ${ }^{8}$ reduce calcium overload and free radical-induced injury, ${ }^{9}$ inhibit cell apoptosis ${ }^{10-12}$ and improve endothelial function. ${ }^{13}$ More recently, trimetazidine has been suggested to inhibit cardiac fibrosis through an $\mathrm{NADPH}$ oxidase-reactive oxygen species-connective tissue growth factor pathway ${ }^{14}$ (see figure 1).

Over the past few decades, several small randomised controlled trials (RCT) have been conducted using trimetazidine in the HF population. These trials investigated symptoms, cardiac function parameters, various quality of life aspects and adverse events, comparing trimetazidine with placebo. Some studies have shown a benefit with trimetazidine in HF. However, the studies showed limited benefits, and the small sample sizes produced underpowered results, and until now metabolic therapy was not recommended by guidelines. ${ }^{1}$ We therefore performed a meta-analysis to explore the potential therapeutic effects of trimetazidine in the management of chronic HF.

\section{METHODS}

\section{Literature search}

Two authors (DG and NN) independently conducted a search for reports of RCT in Medline via PubMED (studies published from 1966 to June 2010), EMBASE (studies published from 1980 to June 2010) and the Cochrane Central Register of Controlled Trials (using the OVID interface for studies published before the second quarter of 2010). The search terms were 'Trimetazidin*', 'VASTAREL*' or 'IDAPTAN*' plus 'heart failure', 'cardiac failure' or 'cardiomyopathy'. Sensitive filters identified clinical research or RCT in the Medline database ${ }^{15}$ and the EMBASE database. ${ }^{16}$ The search was limited to human subjects, with no restriction for language. Conference proceedings from the American College of Cardiology (2005-10), American Heart Association (2005-10), and European Society of Cardiology Congress (2005-10) were also searched. The search was 
Figure 1 Possible mechanisms of the benefit effects of trimetazidine (TMZ) in heart failure (HF): from metabolism to myocardial protection. Administration of trimetazidine induces the partial inhibition of fatty acid $\beta$-oxidation ( $\beta$-ox) and increases pyruvate dehydrogenase (PDH) (1) and determines the increase in glucose oxidation, energetically useful in HF. (2) Limitation of accumulation of sodium and calcium and intracellular acidosis. (3) Reduces reactive oxygen species (ROS)-induced cell damage, and inhibits cardiac fibrosis and inflammation through the ROS/CTGF pathway. (4) Prevention of cell apoptosis through the mitogenactivated protein kinase (MAPK)/AKT pathway. (5) Reduces uncoupling proteins (UCP) and increases PCr/ATP ratio. The final effect is a reduction in

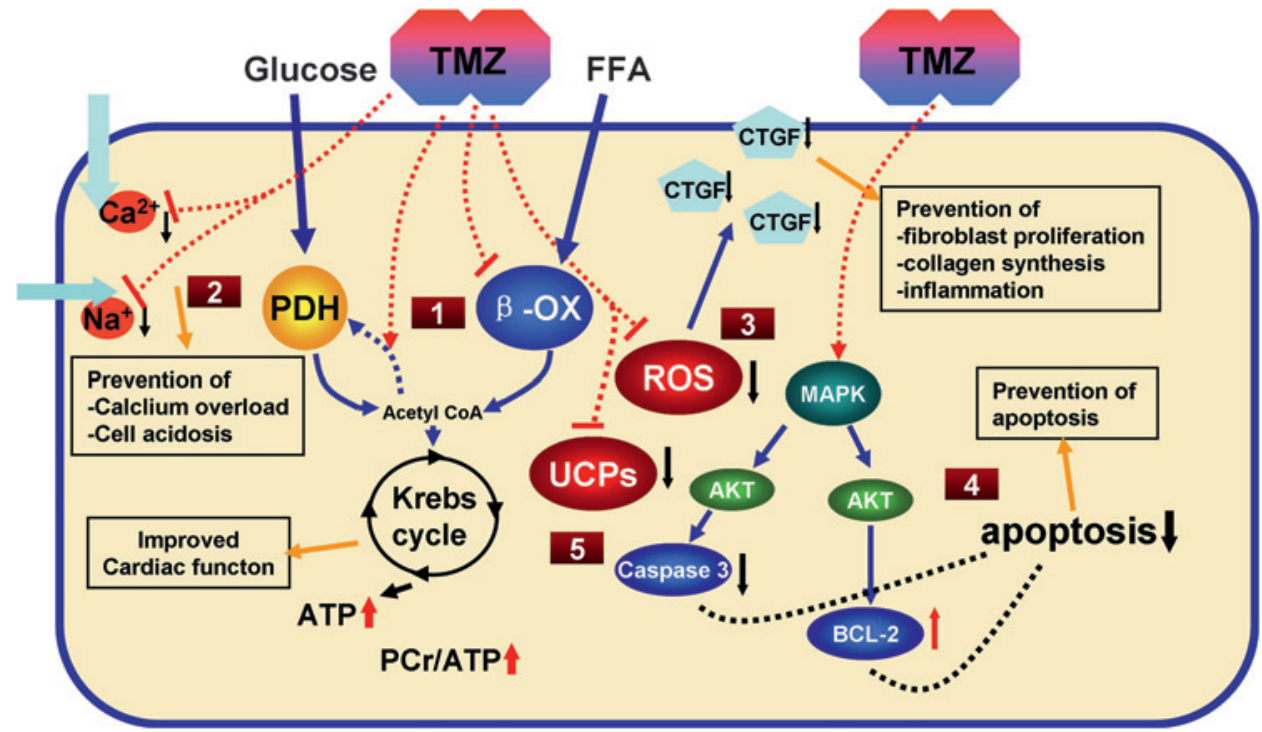
cellular damage and an improvement in HF.

FFA, free fatty acid. PCr, creatine phosphate; CTGF, connective tissue growth factor.

finalised on 18 June 2010. The Clinical Trials database (http:// clinicaltrials.gov/) was searched with the search term 'Trimetazidin*' for articles in other archived registries. We also contacted the manufacturers of trimetazidine (no additional studies were identified) and reviewed the bibliographies of reports of RCT and review articles for possible missed reports of RCT. ${ }^{17}$

\section{Inclusion criteria}

Two authors (DG and NN) reviewed all retrieved abstracts to identify potential reports of RCT. The full texts of potential articles were retrieved and reviewed by the same authors to determine eligible articles. Disagreements were resolved by consensus, and if necessary a third author (XN) was consulted. Reports of RCT of trimetazidine compared with placebo control for chronic HF in adults and reporting at least one of the outcomes of interest were considered eligible. These outcomes included mortality, hospitalisation, cardiovascular events, changes in cardiac function parameters (ie, left ventricular

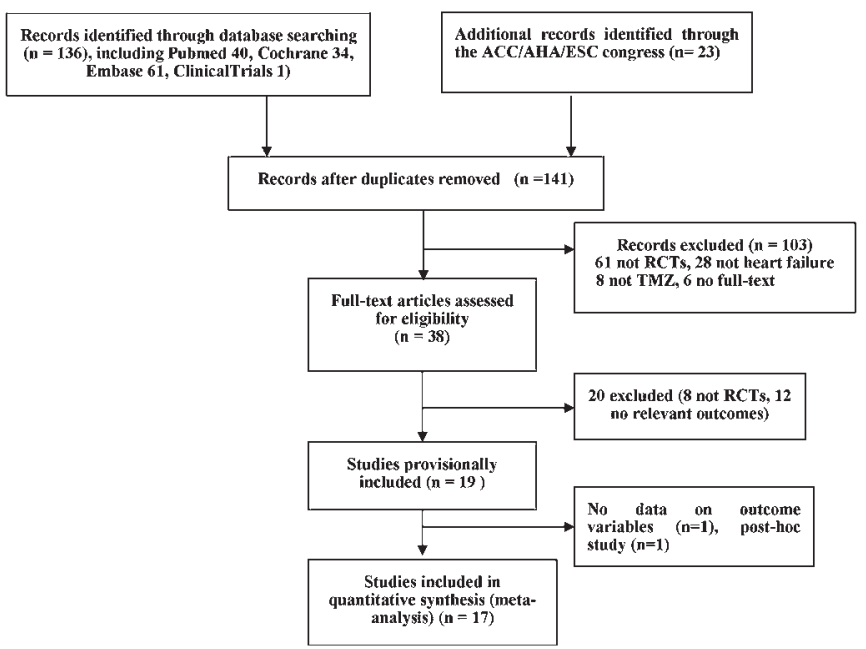

Figure 2 Flow diagram of the trial selection process. ACC, American College of Cardiology; AHA, American Heart Association; ESC, European Society of Cardiology; RCT, randomised controlled trial; TMZ, trimetazidine. ejection fraction (LVEF), left ventricular end-diastolic volume (LVEDV), left ventricular end-systolic volume (LVESV)), New York Heart Association (NYHA) classification and exercise capacity (ie, exercise duration).

\section{Validity assessment and data abstraction}

All included articles were assessed for validity by two authors (DG and NN) independently, with disputes resolved by discussion. The quality of the included RCT was also assessed by the Jadad scale. ${ }^{18}$ If a study did not clearly mention one of these key points, we considered that the point was not covered in the study, and the results may have underestimated the reported characteristics.

Data were abstracted by the use of specific data collection forms by the two authors (DG and NN) and checked for accuracy (by XN). Data were collected on study characteristics (publication data, first author's last name, year of publication, sample size, intervention, comparator therapy, follow-up interval,inclusion criteria and endpoints) and patient characteristics (number of patients, age, gender, cause of the HF, LVEF at baseline, NYHA classification at baseline, other concurrent therapies and the presence of diabetes). When the report did not contain sufficient details to evaluate the validity of the study or outcome data were missing, we attempted to contact the authors by email and in writing. The study complied with the recently reported Preferred Reporting Items for Systematic Reviews and Meta-Analyses (PRISRMA) statement. $^{19}$

\section{Statistical analysis}

We referred to the guidelines of the Cochrane handbook for systematic reviews of interventions ${ }^{20}$ for this meta-analysis. For reports of crossover studies in which the authors did not report the data as mean differences between treatment and control but separately as data for two groups, data were analysed as two separate parallel trials, labelled (a) and (b). For dichotomous outcomes, results were expressed as RR with 95\% CI. For continuous outcomes, pooled data were described with the weighted mean difference (WMD) and 95\% CI. The heterogeneity of results across trials was assessed with a standard $\chi^{2}$ test with significance set at $\mathrm{p}<0.10$ and an $\mathrm{I}^{2}$ statistic with 
Table 1 Quality features of 17 reports of RCT assessed in the meta-analysis

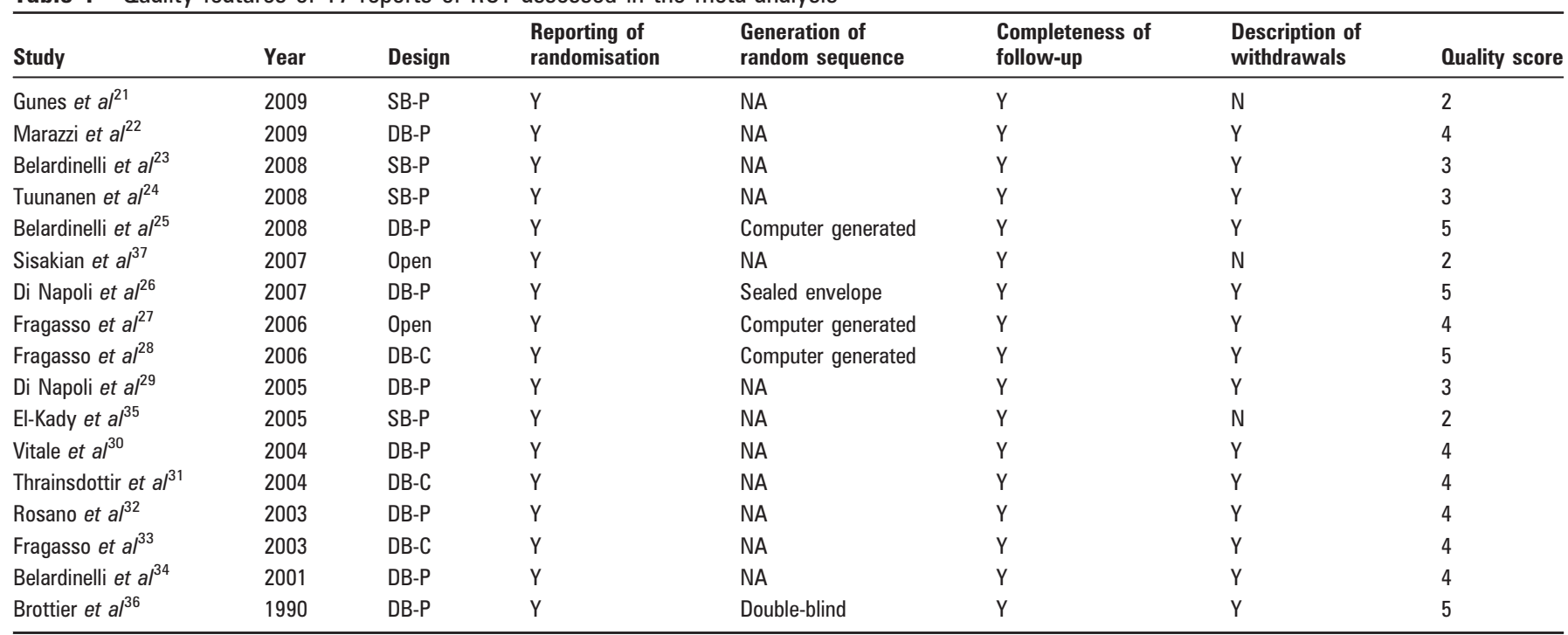

DB-C, double-blind crossover; DB-P, double-blind parallel; NA,unable to assess; RCT, randomised controlled trial; SB-P, single-blind parallel.

significance set at $\mathrm{I}^{2}$ greater than $50 \%$. A random effects model was used for statistical analysis due to wide clinical and methodological variability across the trials. Publication bias was evaluated by the funnel plot. All analyses involved use of review manager version 5.0 (Revman; The Cochrane Collaboration,
Oxford, UK). A value of $\mathrm{p}<0.01$ was considered statistically significant. To evaluate the effect of methodological characteristics of studies on the results of this meta-analysis, the impact of the components of such characteristics on our meta-analysis was assessed by sensitivity analysis.

Table 2 Study characteristics

\begin{tabular}{|c|c|c|c|c|c|}
\hline Study & $\begin{array}{l}\text { Randomised patients } \\
\text { (trimetazidine/ } \\
\text { placebo) }\end{array}$ & $\begin{array}{l}\text { Intervention } \\
\text { (dose/day) }\end{array}$ & $\begin{array}{l}\text { Follow-up } \\
\text { interval }\end{array}$ & Inclusion criteria & Endpoints \\
\hline Gunes et $a l^{21}$ & $87(51 / 36)$ & $60 \mathrm{mg} /$ day & 3 Months & $\begin{array}{l}\text { Chronic stable HF, NYHA } \\
\text { class II-IV, LVEF } \leq 40 \%\end{array}$ & $\begin{array}{l}\text { Echocardiographic parameters, NYHA } \\
\text { class }\end{array}$ \\
\hline Marazzi et $a l^{22}$ & $47(23 / 24)$ & $40 \mathrm{mg} /$ day & 6 Months & $\begin{array}{l}\text { Age } \geq 60 \text { years, chronic stable } \\
\text { ischaemic } H F, L V E F<50 \%\end{array}$ & QOL, NYHA class \\
\hline Belardinelli et $\left.a\right|^{23}$ & $116(60 / 56)$ & $60 \mathrm{mg} /$ day & 8 Weeks & $\begin{array}{l}\text { Stable ischaemic HF, } \\
\text { LVEF } \leq 40 \%\end{array}$ & $\begin{array}{l}\text { Echocardiographic parameters, exercise } \\
\text { testing, blood chemistry }\end{array}$ \\
\hline Tuunanen et $a l^{24}$ & $19(12 / 7)$ & $70 \mathrm{mg} /$ day & 3 Months & IDCM with LVEF $\leq 47 \%$ & $\begin{array}{l}\text { Echocardiographic parameters, } \\
\text { myocardial metabolism, blood chemistry }\end{array}$ \\
\hline Belardinelli et $a l^{25}$ & $34(19 / 16)$ & $60 \mathrm{mg} /$ day & 3 Months & Diabetes, stable ischaemic HF & $\begin{array}{l}\text { Myocardial scintigraphy parameters, } \\
\text { blood chemistry }\end{array}$ \\
\hline Di Napoli et al & $61(30 / 31)$ & $60 \mathrm{mg} / \mathrm{day}$ & 48 Months & $\begin{array}{l}\text { Chronic stable ischaemic HF, } \\
\text { LVEF } \leq 40 \%\end{array}$ & $\begin{array}{l}\text { All-cause mortality, hospitalisation, NYHA } \\
\text { class, exercise capacity, LVEF, CRP }\end{array}$ \\
\hline Sisakian et $a l^{37}$ & $82(42 / 40)$ & $70 \mathrm{mg} /$ day & 3 Months & $\begin{array}{l}\text { Stable ischaemic } \mathrm{HF} \text {, } \\
\text { LVEF }<40 \%\end{array}$ & $\begin{array}{l}\text { Echocardiographic parameters, exercise } \\
\text { capacity, NYHA }\end{array}$ \\
\hline Di Napoli et $\left.a\right|^{26}$ & $50(25 / 25)$ & $60 \mathrm{mg} /$ day & 6 Months & Ischaemic HF, LVEF $\leq 35 \%$ & $\begin{array}{l}\text { Exercise capacity, LVEF, NYHA class, } \\
\text { BNP }\end{array}$ \\
\hline Fragasso et $a l^{27}$ & $65(34 / 31)$ & $60 \mathrm{mg} /$ day & 12 Months & $\begin{array}{l}\text { Chronic stable HF, NYHA } \\
\text { class II to IV, LVEF } \leq 45 \%\end{array}$ & $\begin{array}{l}\text { Hospitalisation, cardiovascular events, } \\
\text { NYHA class, Echocardiographic } \\
\text { parameters, OOL, BNP }\end{array}$ \\
\hline Fragasso et $\left.a\right|^{28}$ & $12 / 12$ & $60 \mathrm{mg} /$ day & 90 Days & Chronic stable HF, LVEF $\leq 45 \%$ & $\begin{array}{l}\text { NYHA class, } \mathrm{QOL} \text {, echocardiographic } \\
\text { parameters, BNP, ergometric results }\end{array}$ \\
\hline El-Kady et $a l^{35}$ & $200(100 / 100)$ & $60 \mathrm{mg} /$ day & 24 Months & Stable ischaemic HF, LVEF $<50 \%$ & SPECT parameters, exercise tests, LVEF \\
\hline Vitale et $a l^{30}$ & $47(23 / 24)$ & $60 \mathrm{mg} /$ day & 6 Months & $\begin{array}{l}\text { Age } \geq 65 \text { years, chronic stable } \\
\text { ischaemic } \mathrm{HF}, \mathrm{LVEF}<50 \%\end{array}$ & $\begin{array}{l}\text { Cardiovascular events, hospitalisation, } \\
\text { echocardiographic parameters, } \mathrm{OOL}\end{array}$ \\
\hline Thrainsdottir et $a l^{31}$ & $20 / 20$ & $60 \mathrm{mg} /$ day & 4 Weeks & $\begin{array}{l}\text { Diabetes, stable ischaemic HF, } \\
\text { NYHA class II-III, LVEF } \leq 40 \%\end{array}$ & $\begin{array}{l}\text { Exercise test, echocardiographic } \\
\text { parameters }\end{array}$ \\
\hline Rosano et $a l^{32}$ & $32(16 / 16)$ & $60 \mathrm{mg} / \mathrm{day}$ & 6 Months & $\begin{array}{l}\text { Diabetes, stable ischaemic HF, } \\
\text { LVEF }<50 \%\end{array}$ & Echocardiographic parameters \\
\hline Fragasso et $a l^{33}$ & $16 / 16$ & $60 \mathrm{mg} /$ day & 6 Months & $\begin{array}{l}\text { Diabetes, stable ischaemic HF, } \\
\text { LVEF } \leq 40 \%\end{array}$ & $\begin{array}{l}\text { Echocardiographic parameters, blood } \\
\text { chemistry parameters }\end{array}$ \\
\hline Belardinelli et $a l^{34}$ & $44(22 / 22)$ & $60 \mathrm{mg} /$ day & 2 Months & Chronic stable cardiomyopathy & $\begin{array}{l}\text { Exercise test, echocardiographic } \\
\text { parameters }\end{array}$ \\
\hline Brottier et $a l^{36}$ & $23(10 / 13)$ & $60 \mathrm{mg} /$ day & 6 Months & Severe ischaemic HF, NYHA III-IV & Echocardiographic parameters \\
\hline
\end{tabular}


Table 3 Patient characteristics

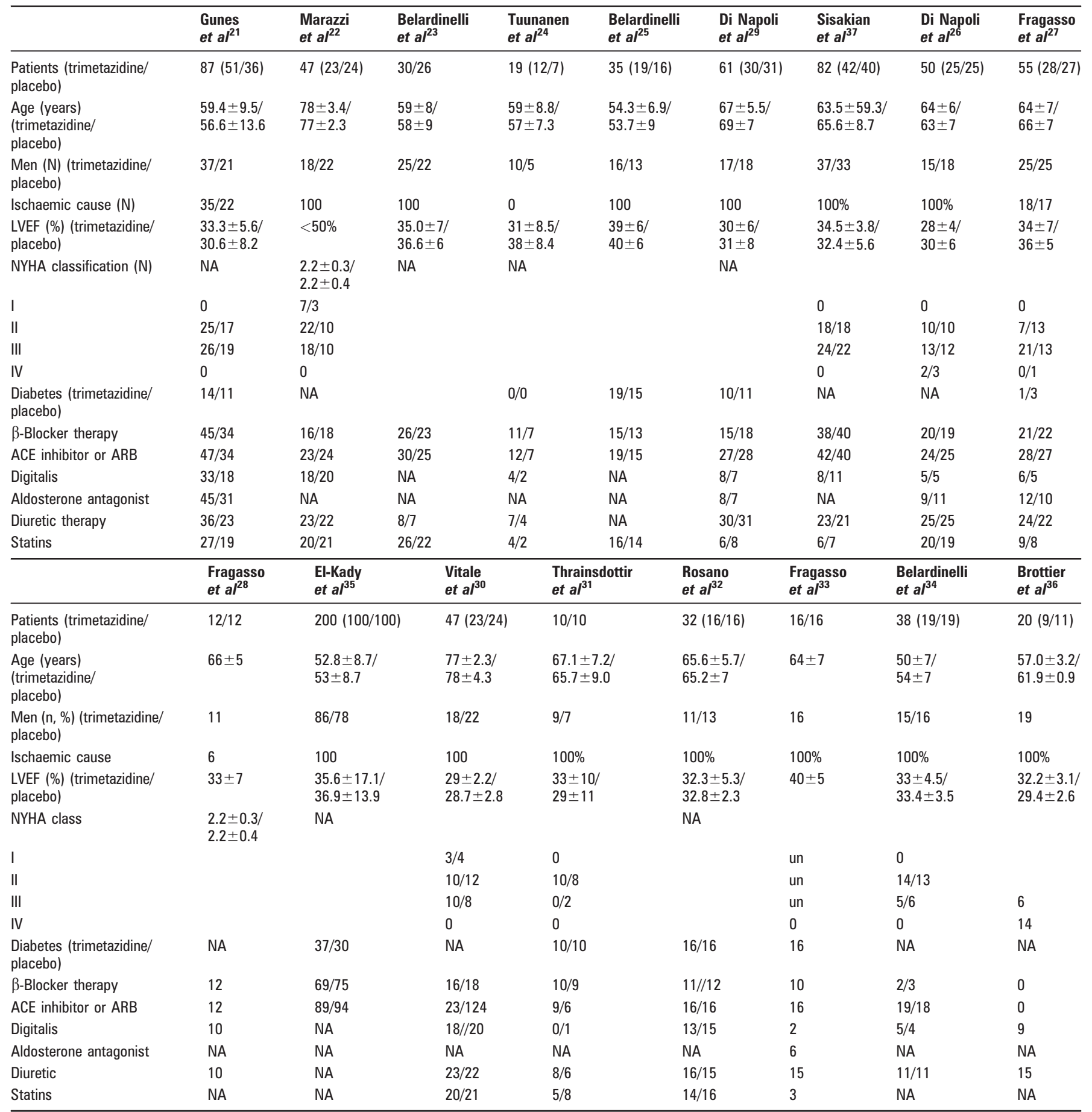

ARB, angiotensin receptor blocker; N, number of patients; NA,unable to assess; LVEF, left ventricular ejection fraction; NYHA, New York Heart Association.

\section{RESULTS}

\section{Study characteristics}

The search revealed 159 reports of RCT of trimetazidine for HF; 38 full-text articles and six abstracts were retrieved for in-depth review. The reports for 17 studies, ${ }^{21-37}$ enrolling 955 participants fulfilled all eligibility criteria, were analysed. Figure 2 shows the flow of studies through the selection process. The validity assessments are shown in table 1 . The trial and patient characteristics are shown in tables 2 and 3, respectively. Reports of 16 trials $^{21} 23-37$ described an evaluation of LVEF $(\mathrm{n}=866), 10^{21} 23-25272830333437$ LVESV and LVEDV ( $\left.\mathrm{n}=491\right)$, $\operatorname{six}^{23} 2728333537$ exercise capacity (exercise duration) ( $n=381$ ), seven 21222627293037 NYHA classification ( $\mathrm{n}=426$ ), four ${ }^{26} 272935$ all-cause mortality $(n=376)$ and four ${ }^{24} 262730$ cardiovascular events and hospitalisation $(n=189)$ during the study periods. Trimetazidine dosage ranged from 60 to $70 \mathrm{mg} /$ day and treatment periods from 4 weeks to 24 months.

\section{Cardiac function}

Left ventricular ejection fraction

Among the 16 reports providing data on LVEF, LVEF was significantly higher for patients who received trimetazidine therapy (WMD 7.49\%; 95\% CI 6.26 to 8.71; p<0.01). Subgroup analysis revealed trimetazidine associated with a significant 
LVEF

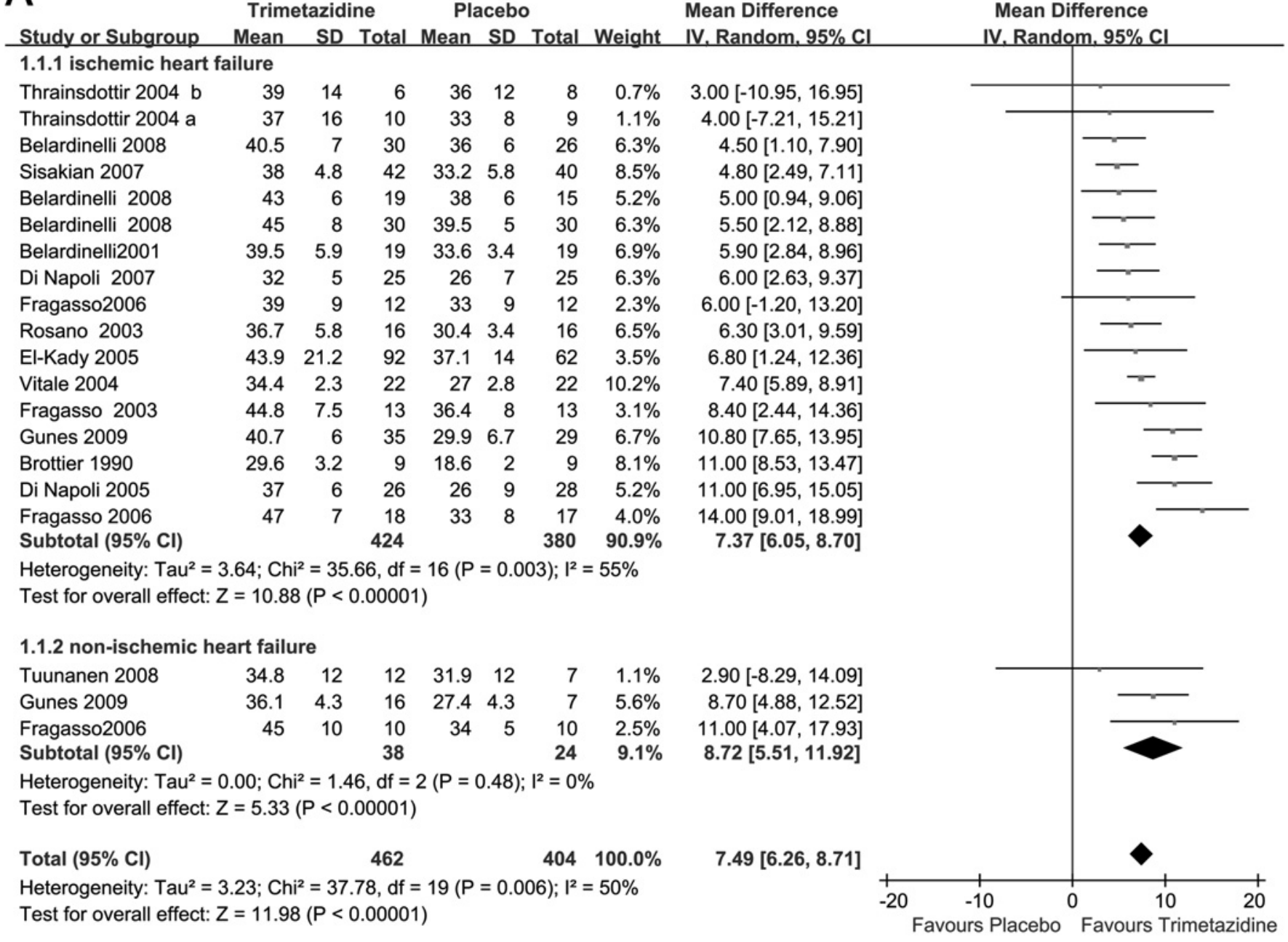

B

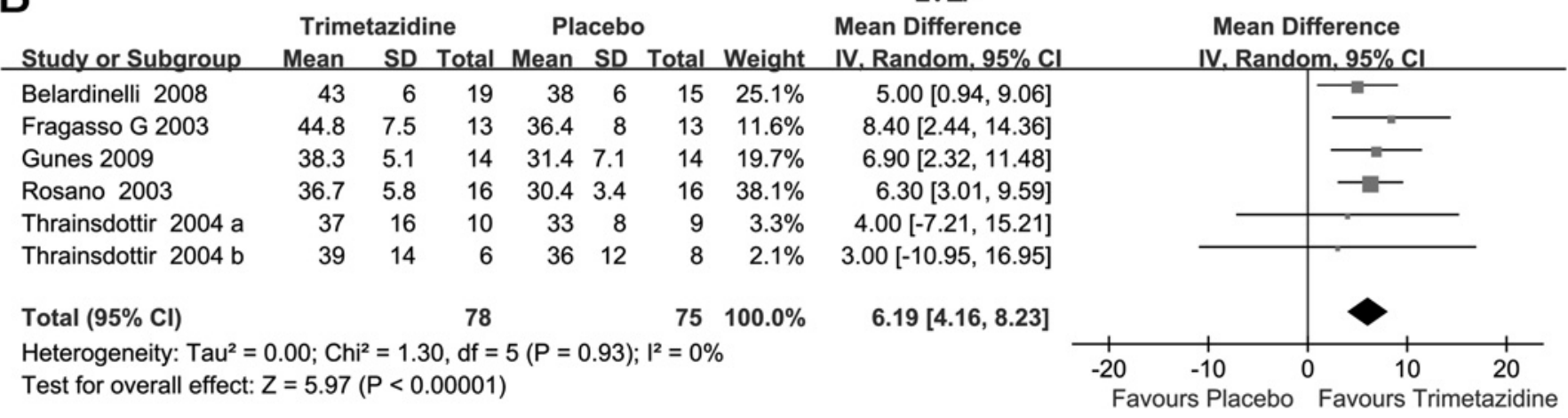

Figure 3 Forest plot from meta-analysis of weighted mean differences in left ventricular ejection fraction (LVEF) for patients with heart failure (HF) receiving trimetazidine (TMZ) or placebo. Subgroup analysis of the effect in patients with ischaemic HF, non-ischaemic HF (A) and patients with diabetes with HF (B). IV, inverse variance.

improvement in LVEF for patients with both ischaemic (WMD $7.37 \%$; 95\% CI 6.05 to $8.70 ; \mathrm{p}<0.01$ ) and non-ischaemic HF (WMD 8.72\%; 95\% CI 5.51 to 11.92; $<<0.01$ ) (figure 3A). For the subgroup of patients with diabetes with ischaemic HF, LVEF was similarly elevated in response to trimetazidine treatment (WMD 6.19\%; 95\% CI 4.16 to 8.23; p<0.01) (figure 3B). The results of the subgroup and sensitivity analyses are displayed in table 4. As shown in table 4, the LVEF response to trimetazidine was still pronounced in studies of which standard therapies for HF (concomitant use of ACE inhibitors/angiotensin receptor blockers (ARB) and $\beta$-blockers) were used (WMD 7.14\%; 95\% CI 5.99 to $8.30 ; p<0.01)$. In trials that included patients of NYHA classification IV, a more profound improvement in LVEF was found (WMD 10.87\%; 95\% CI 9.39 to 12,35 ; $\mathrm{p}<0.01$ ). The effect of the follow-up interval on the result was also analysed. After excluding the trials that lasted less than 3 months, a profound improvement in LVEF was observed (WMD 8.12\%; 95\% CI 6.68 to $9.55 ; \mathrm{p}<0.01)$. In addition, we renewed the analysis according to methodological quality (excluding scores less than three). There was still a significant improvement in LVEF with 
Table 4 Sensitivity and subgroup analyses

\begin{tabular}{|c|c|c|c|c|}
\hline & $\begin{array}{l}\text { RCT } \\
\text { (n) }\end{array}$ & $\begin{array}{l}\text { p Value for } \\
\text { heterogeneity }\end{array}$ & $95 \% \mathrm{CI}$ & $\begin{array}{l}\text { p Value for } \\
\text { overall effect }\end{array}$ \\
\hline Ischaemic HF & 15 & $\mathrm{p}=0.0009, \mathrm{l}^{2}=63 \%$ & $7.37(6.05$ to 8.70$)$ & $<0.00001$ \\
\hline Non-ischaemic HF & 3 & $\mathrm{p}=0.48, \mathrm{I}^{2}=0 \%$ & $8.72(5.51$ to 11.92$)$ & $<0.00001$ \\
\hline Ischaemic HF with diabetes & 5 & $p=0.93,1^{2}=0 \%$ & $6.19(4.16$ to 8.23$)$ & $<0.00001$ \\
\hline Excluding crossover effect & 14 & $\mathrm{p}=0.002, \mathrm{I}^{2}=57 \%$ & $7.61(6.31$ to 8.92$)$ & $<0.00001$ \\
\hline Trials that did not include class IV HF & 13 & $p=0.62,\left.\right|^{2}=0 \%$ & 6.39 (5.52 to 7.27$)$ & $<0.00001$ \\
\hline Trials that include class IV HF & 3 & $p=0.60, I^{2}=0 \%$ & $10.87(9.39$ to 12.35$)$ & $<0.00001$ \\
\hline $\begin{array}{l}\text { Trials with concomitant us of ACE } \\
\text { inhibitor/ARB and } \beta \text {-blocker }\end{array}$ & 15 & $\mathrm{p}=0.05, \mathrm{I}^{2}=38 \%$ & $7.14(5.99$ to 8.30$)$ & $<0.00001$ \\
\hline $\begin{array}{l}\text { Trials without concomitant use of ACE } \\
\text { inhibitor/ARB and } \beta \text {-blocker }\end{array}$ & 1 & NA & 11.0 (8.53 to 11.47$)$ & $<0.00001$ \\
\hline Jadad scale $\geq 3$ & 13 & $p=0.03,1^{2}=43 \%$ & $7.52(6.22$ to 8.82$)$ & $<0.00001$ \\
\hline Follow-up interval $\geq 3$ & 13 & $p=0.006, I^{2}=55 \%$ & 8.12 (6.68 to 9.55$)$ & $<0.00001$ \\
\hline
\end{tabular}

trimetazidine compared with placebo control (WMD 7.52\%; 95\% CI 6.22 to 8.82; p<0.01). A funnel plot of all studies evaluating LVEF appeared symmetrical, thus indicating the low likelihood of publication bias (figure 4).

\section{Left ventricular end-systolic volume and left ventricular end-diastolic volume}

LVESV was significantly lower in patients who received trimetazidine therapy than placebo treatment (WMD $-10.37 \mathrm{ml}$; $95 \%$ CI -15.46 to $-5.29 ; \mathrm{p}<0.01$ ) (figure 5 ). LVEDV was not significantly decreased in response to trimetazidine treatment (WMD $-4.70 \mathrm{ml}$; 95\% CI -11.07 to 1.67 ; $\mathrm{p}=0.15$ ).

\section{Clinical symptoms}

NYHA classification

For the seven reports containing data on NYHA classification, trimetazidine therapy resulted in a significant improvement in NYHA classification compared with placebo (WMD $-0.41 ; 95 \%$ $\mathrm{CI}-0.51$ to $-0.31 ; \mathrm{p}<0.01$ ) (figure $6 \mathrm{~A}$ ).

\section{Exercise capacity}

For the six reports containing data for exercise capacity, trimetazidine significantly increased exercise duration compared with placebo control (WMD 30.26 s; 95\% CI 8.77 to 51.75 ; $\mathrm{p}=0.01$ ) (figure 6B).

\section{Major adverse events}

For the four reports containing data on mortality, with trimetazidine treatment mortality was lower than that with

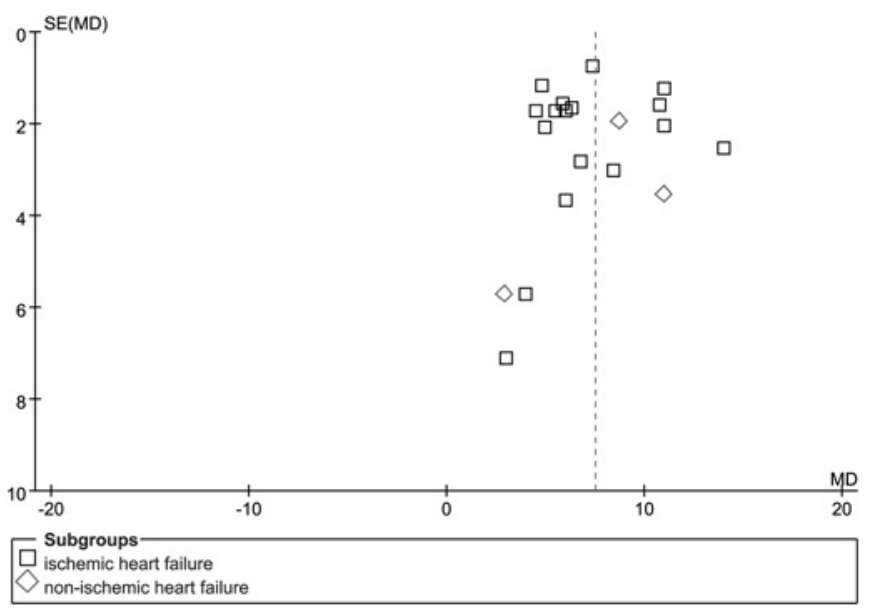

Figure 4 Funnel plot assessing evidence of publication bias from 16 trials. placebo (7.5\%; 14/187 patients vs $27.5 \%$; 52/189 patients), for a significant protective effect of trimetazidine treatment on mortality with HF (RR 0.29 ; 95\% CI 0.17 to 0.49 ; $p<0.01$ ) (figure 7A).

Cardiovascular events and hospitalisation data reported for four trials revealed a significant decrease in these conditions with trimetazidine treatment (RR $0.42 ; 95 \%$ CI $0.30-0.58 ; \mathrm{p}<0.01$ ) (figure 7B).

\section{DISCUSSION}

We performed a meta-analysis of RCT evaluating the effect of trimetazidine compared with placebo control on cardiac function variables, clinical symptoms and major adverse events in patients with chronic HF. We found trimetazidine treatment resulted in better cardiac function for ischaemic and non-ischaemic HF, and improved clinical symptoms. More importantly, trimetazidine was associated with a significant reduction in the $R R$ for mortality, cardiovascular events and hospitalisation.

Trimetazidine is initially used as an anti-ischaemic or 'cytoprotective' agent through a metabolic pathway: switching cardiac metabolism from FFA to glucose oxidation, which is efficient in terms of oxygen consumption and energy production. Because FFA inhibitors can act as metabolic modulators in protecting the ischaemic myocardium, the effects of trimetazidine on HF have previously been assessed mainly in patients with ischaemic HF. The results of several small RCT have revealed improved cardiac function with trimetazidine. By pooling these results, our meta-analysis confirms increased LVEF in response to trimetazidine treatment in ischaemic HF. Because we included studies that were published over a long period (1990-2010), changes in practice over time could have an effect on the results. We observed a more profound effect of trimetazidine on LVEF (11\%) in the study by Brottier et al ${ }^{36}$ in which ACE inhibitors/ARB or $\beta$-blockers were not used. Sensitivity analysis of the trials that ACE inhibitors/ARB and $\beta$-blockers were concomitantly used resulted in a WMD for LVEF of $7.49 \%$ to $7.14 \%(p<0.01)$, with reduced heterogeneity ( $I^{2}$ from $50 \%$ to $38 \%$ ). This indicates that trimetazidine may improve cardiac function even with the concomitant use of current standard therapies. Trimetazidine was recently found to have cardioprotective effects in patients with HF of different aetiologies other than ischaemic HF. ${ }^{21} 2427$ We pooled the results for LVEF from three trials of non-ischaemic HF in response to trimetazidine treatment and showed a significant improvement ( $8.72 \%$ ) of LVEF with trimetazidine. Several lines of evidence suggest that high plasma levels of FFA and high rates of fatty acid oxidation in the myocardium results in impaired 
A

\begin{tabular}{l} 
Study or Subgroup \\
\hline Sisakian 2007 \\
Vitale 2004 \\
Belardinelli 2008 \\
Fragasso2006 \\
Gunes 2009 \\
Belardinelli 2008 \\
Tuunanen 2008 \\
Belardinelli2001 \\
Fragasso 2006 \\
Fragasso 2003
\end{tabular}

Total $(95 \% \mathrm{Cl})$

Heterogeneity: $\mathrm{Tau}^{2}=31.32 ; \mathrm{Chi}^{2}=26.46, \mathrm{df}=9(\mathrm{P}=0.002) ; \mathrm{I}^{2}=66 \%$

Test for overall effect: $Z=4.00(P<0.0001)$
LVESV

Mean Difference Mean Difference

$-19.00[-27.48,-10.52]$

$7.40[-20.88,-13.92]$

$-6.00[-11.06,-0.94]$

$-9.00[-54.26,36.26]$

$-11.60[-26.16,2.96]$

$-7.00[-12.24,-1.76]$

$18.00[-75.08,111.08]$

$-2.50[-10.77,5.77]$

$-8.00[-24.26,8.26]$

$-13.80[-46.36,18.76]$

$-10.37[-15.46,-5.29]$

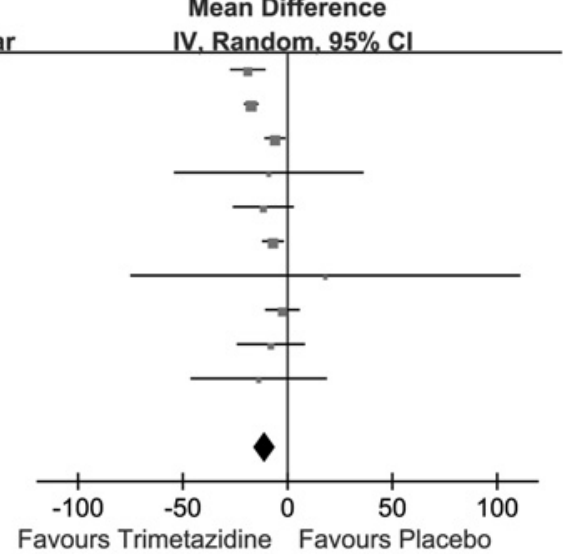

B

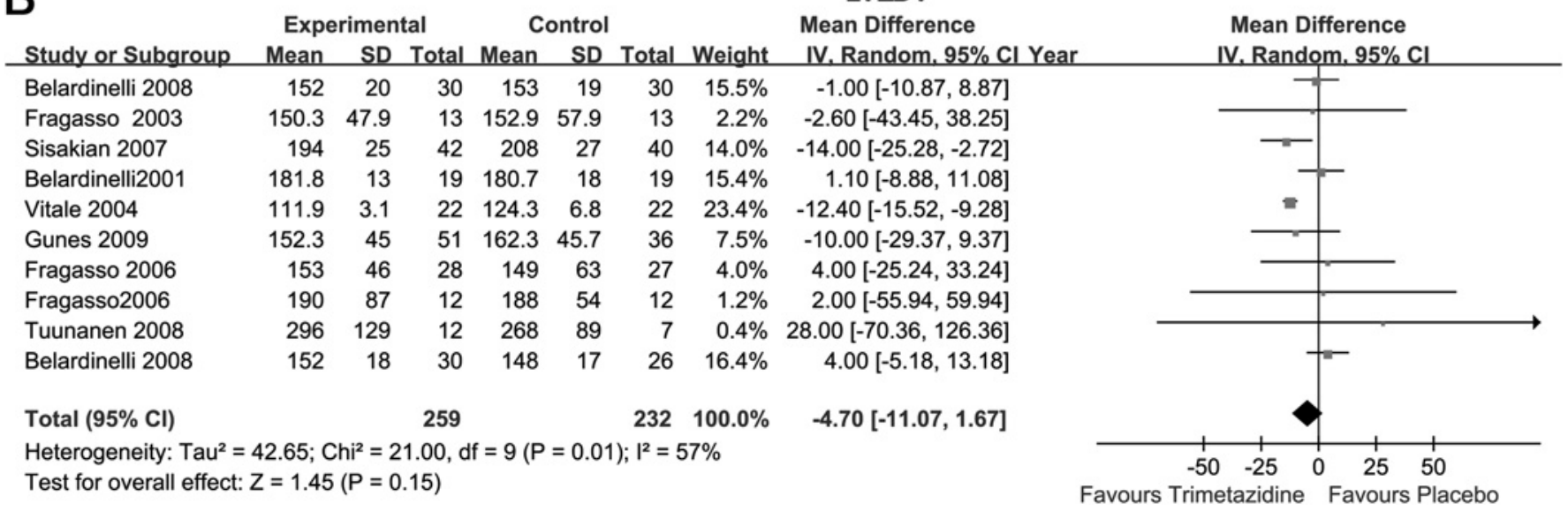

Figure 5 Forest plot of weighted mean differences for left ventricular end-systolic volume (LVESV) (A) and left ventricular end-diastolic volume (LVEDV) (B) for patients with heart failure receiving trimetazidine or placebo. IV, inverse variance.

contractile function and a higher incidence of ventricular arrhythmias during and after myocardial ischaemia in the diabetic heart. ${ }^{38}$ Therefore, trimetazidine might have more benefit in patients with diabetes with HF. However, our pooled results showed a similar improvement in LVEF in this subgroup (WMD $6.19 \% ; 95 \%$ CI 4.16 to 8.23 ). A mechanism other than an energy modulator, which positively redirects the neurohormonal pathway $^{39}$ or inhibits cardiac fibrosis through an NADPH oxidase-reactive oxygen species connective tissue growth factor pathway, ${ }^{14}$ may contribute to this effect.

Improving clinical symptoms is an important treatment goal in HF. Our pooled results revealed an improvement in NYHA classification and exercise capacity (exercise duration) with trimetazidine. As a result of a lack of these outcomes, we cannot estimate the differential changes in NYHA classification and exercise capacity by different aetiologies. We found significant heterogeneity in our meta-analysis of exercise capacity $\left(I^{2}=85 \%\right)$. Differences in baseline exercise capacity and cardiac function may contribute to this heterogeneity.

In patients with $\mathrm{HF}$, the effect of trimetazidine on mortality and other main outcomes is still controversial. Only four reports of RCT with small samples ${ }^{26} 27 \quad 2935$ described all-cause mortality, and four described ${ }^{24262730}$ cardiovascular events and hospitalisation. The pooled results from our study indicate that trimetazidine provided a significant protective effect on decreasing the risk of all-cause mortality, cardiovascular events and hospitalisation. Given the relatively small sample sizes of the studies, we cannot estimate the effect of trimetazidine by different aetiologies, and more importantly the overall effect of trimetazidine on mortality in chronic HF should be tested in large-scale, randomised controlled clinical trials.

Some limitations of our meta-analysis need to be acknowledged. First, the methodological quality of the studies included in this analysis was less than optimal, with only five studies meeting all the validity criteria. Four studies were limited by their single-blind design. Three studies were open label, and three studies did not report blinding. We were not able to exclude the potential risk of bias in these trials. Second, the number of patients included in this meta-analysis was small, so some estimates such as for all-cause mortality, cardiovascular events and hospitalisation are based on relatively small numbers of measurements. However, we tried to include all available trials, and we did observe some benefits (including cardiac function, clinical symptoms and hard endpoints) associated with trimetazidine use. As a result of the small sample size, there is a probability of overestimating the clinical benefit if one does not exist (type I error). Results from our meta-anlaysis should be interpreted with caution. Third, we did not have access to individual patient data. Subgroups of HF patients might show a difference with trimetazidine treatment, but we could not perform these analyses given the limited number of patients for the currently available reports, especially for major adverse events. Finally, the follow-up times varied widely, from 4 weeks to 48 months. 
A

\begin{tabular}{lrrrrrrrrr} 
& \multicolumn{1}{c}{ Trimetazidine } & \multicolumn{4}{c}{ Placebo } & \multicolumn{1}{c}{ Mean Difference } \\
Study or Subgroup & Mean & SD & Total & Mean & SD & Total & Weight & IV. Random, 95\% Cl \\
\hline Sisakian 2007 & 1.84 & 0.3 & 42 & 2.3 & 0.3 & 40 & $36.9 \%$ & $-0.46[-0.59,-0.33]$ \\
Di Napoli 2005 & 2.63 & 0.67 & 30 & 2.81 & 0.65 & 31 & $8.6 \%$ & $-0.18[-0.51,0.15]$ \\
Fragasso2006 & 2 & 0.47 & 28 & 2.44 & 0.58 & 27 & $11.7 \%$ & $-0.44[-0.72,-0.16]$ \\
Gunes 2009 & 2.04 & 0.2 & 51 & 2.39 & 0.49 & 36 & $26.1 \%$ & $-0.35[-0.52,-0.18]$ \\
Vitale 2004 & 2.05 & 0.84 & 22 & 2.82 & 0.66 & 22 & $5.0 \%$ & $-0.77[-1.22,-0.32]$ \\
marazzi 2009 & 2 & 0.8 & 23 & 2.63 & 0.92 & 24 & $4.1 \%$ & $-0.63[-1.12,-0.14]$ \\
Di Napoli 2007 & 2.6 & 0.58 & 25 & 2.84 & 0.69 & 25 & $7.7 \%$ & $-0.24[-0.59,0.11]$ \\
Total (95\% Cl) & & & & & & & & \\
& & & 221 & & & 205 & $100.0 \%$ & $-0.41[-0.51,-0.31]$
\end{tabular}

Heterogeneity: $\mathrm{Tau}^{2}=0.00 ; \mathrm{Chi}^{2}=7.09, \mathrm{df}=6(\mathrm{P}=0.31) ; \mathrm{I}^{2}=15 \%$

Test for overall effect: $Z=7.86(P<0.00001)$

\section{NYHAclass}

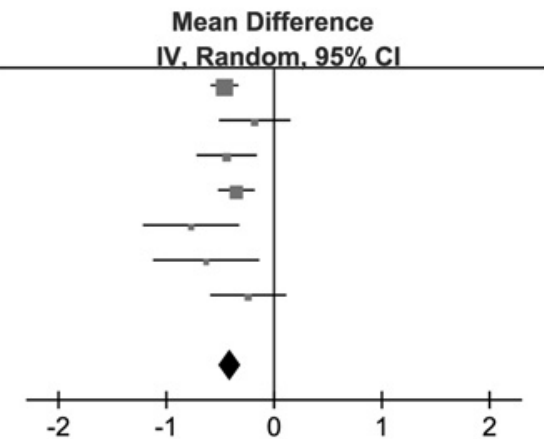

Favours Trimetazidine Favours Placebo

\section{B}

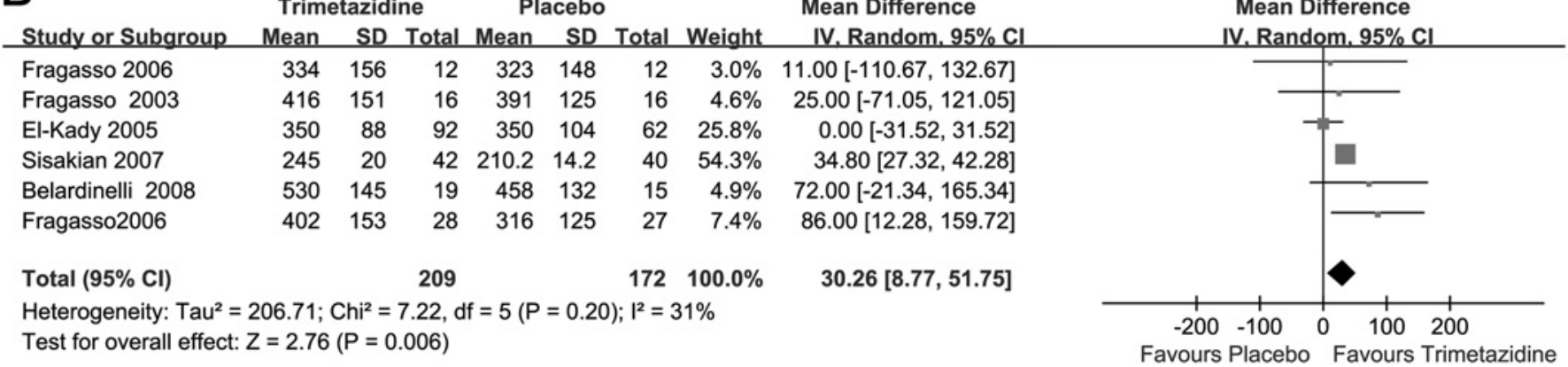

Figure 6 Forest plot of weighted mean differences for New York Heart Association classification (NYHA) (A) and exercise duration (B) for patients with heart failure receiving trimetazidine or placebo. IV, inverse variance.

In conclusion, our meta-analysis shows that trimetazidine improves systolic function and clinical symptoms for patients with chronic HF, as shown by a significant change in systolic function, NYHA classification and exercise duration. Moreover, these improvements associated with trimetazidine may result in reduced all-cause mortality, cardiovascular events and hospitalisation after long-term treatment. Given these results, largescale, prospectively designed, randomised, double-blinded trials are still required to clarify some of these questions. Trimetazidine might be a choice for patients with chronic HF, especially

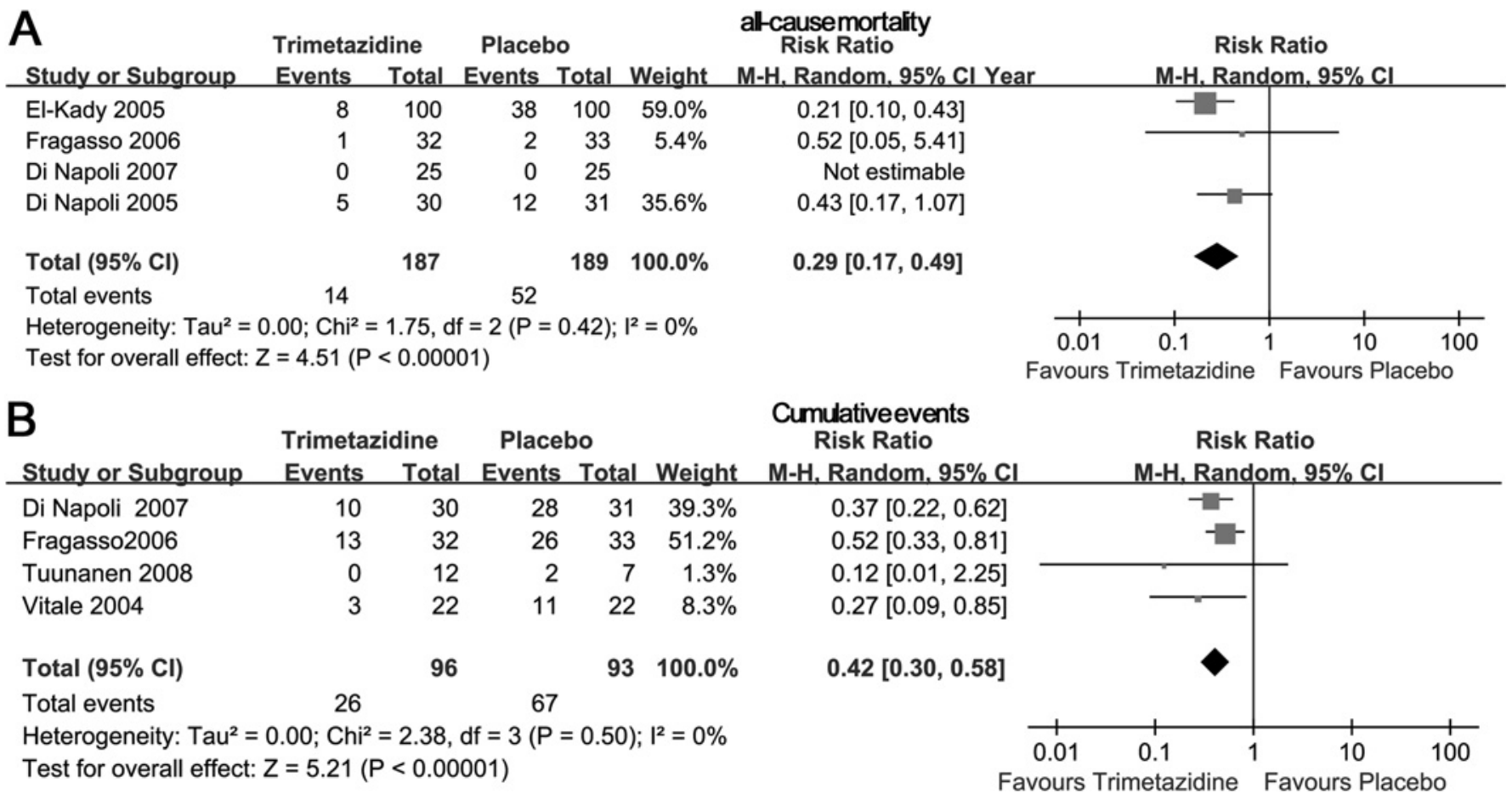

Figure 7 Comparison of clinical outcomes of patients with heart failure receiving trimetazidine or placebo for (A) all-cause mortality and (B) cumulative events. $\mathrm{M}-\mathrm{H}$, Mantel-Haenzel. 
those with ischaemic HF, even for whom current standard therapies are used. However, until now, we cannot recommend the routine use of trimetazidine for the treatment of HF.

Funding This study was supported by a grant from the National Natural Science Foundation of China (no 30900617 to DG), Research Fund for the Doctoral Program of Higher Education of China (no 2008.6981036 to DG), and Major Basic Research Development Program of China from the Ministry of Science and Technology (no 2006 CB503802 to XN).

Competing interests None to declare.

Patient consent Obtained.

Provenance and peer review Not commissioned; externally peer reviewed.

\section{REFERENCES}

1. Lloyd-Jones D, Adams R, Carnethon M, et al. Heart disease and stroke statistics 2009 update: a report from the American Heart Association Statistics Committee and Stroke Statistics Subcommittee. Circulation 2009;119:e21-181.

2. Hunt SA, Abraham WT, Chin MH, et al. 2009 Focused update incorporated into the ACC/AHA 2005 guidelines for the diagnosis and management of heart failure in adults: a report of the American College of Cardiology Foundation/American Heart Association Task Force on Practice Guidelines developed in collaboration with the International Society for Heart and Lung Transplantation. J Am Coll Cardiol 2009;53:e1-90

3. Najafi F, Jamrozik K, Dobson AJ. Understanding the 'epidemic of heart failure': a systematic review of trends in determinants of heart failure. Eur $\mathrm{J}$ Heart Fail 2009;11:472-9.

4. Palaniswamy C, Mellana WM, Selvaraj DR, et al. Metabolic modulation: a new therapeutic target in treatment of heart failure. Am J Ther. Published Online First: 10 April 2010.

5. Di Napoli P, Barsotti A. Prognostic relevance of metabolic approach in patients with heart failure. Curr Pharm Des 2009;15:883-92.

6. Fragasso G, Spoladore R, Cuko A, et al. Modulation of fatty acids oxidation in heart failure by selective pharmacological inhibition of 3-ketoacyl coenzyme-A thiolase. Curr Clin Pharmacol 2007:2:190-6.

7. Fantini E, Demaison L, Sentex E, et al. Some biochemical aspects of the protective effect of trimetazidine on rat cardiomyocytes during hypoxia and reoxygenation. J Mol Cell Cardiol 1994;26:949-58.

8. Bertomeu-Gonzalez V, Bouzas-Mosquera A, Kaski JC. Role of trimetazidine in management of ischemic cardiomyopathy. Am J Cardiol 2006;98:19J-24J.

9. Onay-Besikci A, Ozkan SA. Trimetazidine revisited: a comprehensive review of the pharmacological effects and analytical techniques for the determination of trimetazidine. Cardiovasc Ther 2008;26:147-65.

10. Khan M, Meduru S, Mostafa M, et al. Trimetazidine, administered at the onset of reperfusion, ameliorates myocardial dysfunction and injury by activation of p38 mitogen-activated protein kinase and Akt signaling. J Pharmacol Exp Ther 2010:333:421-9.

11. Yin RX, Liang WW, Liu TW, et al. Inhibitory effect of trimetazidine on cardiac myocyte apoptosis in rabbit model of ischemia-reperfusion. Chin Med Sci J 2004:19:242.

12. Wisel S, Khan M, Kuppusamy ML, et al. Pharmacological preconditioning of mesenchymal stem cells with trimetazidine (1-[2,3,4-trimethoxybenzyl]piperazine) protects hypoxic cells against oxidative stress and enhances recovery of myocardial function in infarcted heart through Bcl-2 expression. J Pharmacol Exp Ther 2009; 329:543-50

13. Park KH, Park WJ, Kim MK, et al. Effects of trimetazidine on endothelial dysfunction after sheath injury of radial artery. Am J Cardiol 2010;105:1723-7.

14. Liu $\mathbf{X}$, Gai $Y$, Liu F, et al. Trimetazidine inhibits pressure overload-induced cardiac fibrosis through NADPH oxidase-ROS-CTGF pathway. Cardiovasc Res 2010;88:150-8

15. Haynes RB, McKibbon KA, Wilczynski NL, et al. Optimal search strategies for retrieving scientifically strong studies of treatment from Medline: analytical survey. BMJ 2005:330:1179.
16. Wong SS, Wilczynski NL, Haynes RB. Developing optimal search strategies for detecting clinically sound treatment studies in EMBASE. J Med Libr Assoc 2006:94:41-7

17. Hopewell S, McDonald S, Clarke M, et al. Grey literature in meta-analyses of randomized trials of health care interventions. Cochrane Database Syst Rev 2007;(2): MR000010.

18. Jadad AR, Moore RA, Carroll D, et al. Assessing the quality of reports of randomized clinical trials: is blinding necessary? Control Clin Trials 1996;17:1-12

19. Moher D, Liberati A, Tetzlaff J, et al. Preferred reporting items for systematic reviews and meta-analyses: the PRISMA statement. BMJ 2009;339:b2535.

20. Higgins JPT, Green S. Cochrane Collaboration. Cochrane handbook for systematic reviews of interventions. Chichester, England; Hoboken, NJ: Wiley-Blackwell, 2008.

21. Gunes $\mathbf{Y}$, Guntekin $U$, Tuncer $\mathbf{M}$, et al. Improved left and right ventricular functions with trimetazidine in patients with heart failure: a tissue Doppler study. Heart Vessels 2009:24:277-82

22. Marazzi G, Gebara 0, Vitale C, et al. Effect of trimetazidine on quality of life in elderly patients with ischemic dilated cardiomyopathy. Adv Ther 2009:26:455-61.

23. Belardinelli R, Lacalaprice F, Faccenda E, et al. Trimetazidine potentiates the effects of exercise training in patients with ischemic cardiomyopathy referred for cardiac rehabilitation. Eur J Cardiovasc Prev Rehabil 2008:15:533-40.

24. Tuunanen H, Engblom E, Naum A, et al. Trimetazidine, a metabolic modulator, has cardiac and extracardiac benefits in idiopathic dilated cardiomyopathy. Circulation 2008:118:1250-8.

25. Belardinelli R, Cianci G, Gigli M, et al. Effects of trimetazidine on myocardial perfusion and left ventricular systolic function in type 2 diabetic patients with ischemic cardiomyopathy. J Cardiovasc Pharmacol 2008:51:611-15.

26. Di Napoli P, Di Giovanni P, Gaeta MA, et al. Beneficial effects of trimetazidine treatment on exercise tolerance and B-type natriuretic peptide and troponin T plasma levels in patients with stable ischemic cardiomyopathy. Am Heart 2007; 154:602.e1-5.

27. Fragasso G, Palloshi A, Puccetti $\mathrm{P}$, et al. A randomized clinical trial of trimetazidine a partial free fatty acid oxidation inhibitor, in patients with heart failure. J Am Coll Cardiol 2006;48:992-8

28. Fragasso G, Perseghin G, De Cobelli F, et al. Effects of metabolic modulation by trimetazidine on left ventricular function and phosphocreatine/adenosine triphosphate ratio in patients with heart failure. Eur Heart $J$ 2006;27:942-8.

29. Di Napoli P, Taccardi AA, Barsotti A. Long term cardioprotective action of trimetazidine and potential effect on the inflammatory process in patients with ischaemic dilated cardiomyopathy. Heart 2005:91:161-5.

30. Vitale C, Wajngaten M, Sposato B, et al. Trimetazidine improves left ventricular function and quality of life in elderly patients with coronary artery disease. Eur Heart $J$ 2004:25:1814-21.

31. Thrainsdottir IS, von Bibra H, Malmberg K, et al. Effects of trimetazidine on left ventricular function in patients with type 2 diabetes and heart failure. $J$ Cardiovas Pharmacol 2004:44:101-8.

32. Rosano GM, Vitale C, Sposato B, et al. Trimetazidine improves left ventricular function in diabetic patients with coronary artery disease: a double-blind placebocontrolled study. Cardiovasc Diabetol 2003;2:16.

33. Fragasso G, Piatti PM, Monti L, et al. Short- and long-term beneficial effects of trimetazidine in patients with diabetes and ischemic cardiomyopathy. Am Heart J 2003;146:E18. doi:10.1097/MJT.0b013e3181d70453.

34. Belardinelli R, Purcaro A. Effects of trimetazidine on the contractile response of chronically dysfunctional myocardium to low-dose dobutamine in ischaemic cardiomyopathy. Eur Heart J 2001;22:2164-70.

35. El-Kady T, El-Sabban K, Gabaly M, et al. Effects of trimetazidine on myocardial perfusion and the contractile response of chronically dysfunctional myocardium in ischemic cardiomyopathy: a 24-month study. Am J Cardiovasc Drugs 2005;5:271-8.

36. Brottier L, Barat JL, Combe C, et al. Therapeutic value of a cardioprotective agent in patients with severe ischaemic cardiomyopathy. Eur Heart J 1990;11:207-12.

37. Sisakian $\mathbf{H}$, Torgomyan A, Barkhudaryan A. The effect of trimetazidine on left ventricular systolic function and physical tolerance in patients with ischaemic cardiomyopathy. Acta Cardiol 2007;62:493-9.

38. Lopaschuk GD. Abnormal mechanical function in diabetes: relationship to altered myocardial carbohydrate/lipid metabolism. Coron Artery Dis 1996;7:116-23.

39. Di Napoli P, Taccardi AA. Trimetazidine: the future of cardiac function? Future Cardiol 2009:5:421-4. 